\title{
PLA-Based Hybrid and Composite Electrospun Fibrous Scaffolds as Potential Materials for Tissue Engineering
}

\author{
Anna Magiera, ${ }^{1}$ Jarosław Markowski, ${ }^{2}$ Elzbieta Menaszek, ${ }^{3}$ \\ Jan Pilch, ${ }^{2}$ and Stanislaw Blazewicz ${ }^{4}$ \\ ${ }^{1}$ Department of Heat Engineering and Environment Protection, Faculty of Metals Engineering and Industrial Computer Science, \\ AGH University of Science and Technology, 30 Mickiewicza Avenue, 30-059 Krakow, Poland \\ ${ }^{2}$ Laryngology Department, School of Medicine, Medical University of Silesia, 20 Francuska Str., 40-752 Katowice, Poland \\ ${ }^{3}$ Department of Cytobiology, Collegium Medicum, Jagiellonian University, 9 Medyczna Str., 30-068 Krakow, Poland \\ ${ }^{4}$ Department of Biomaterials, Faculty of Materials Science and Ceramics, AGH University of Science and Technology, \\ 30 Mickiewicza Avenue, 30-059 Krakow, Poland \\ Correspondence should be addressed to Stanislaw Blazewicz; blazew@agh.edu.pl
}

Received 25 May 2017; Accepted 26 July 2017; Published 30 August 2017

Academic Editor: Zafar Iqbal

Copyright ( 2017 Anna Magiera et al. This is an open access article distributed under the Creative Commons Attribution License, which permits unrestricted use, distribution, and reproduction in any medium, provided the original work is properly cited.

\begin{abstract}
The aim of the study was to manufacture poly(lactic acid)- (PLA-) based nanofibrous nonwovens that were modified using two types of modifiers, namely, gelatin- (GEL-) based nanofibres and carbon nanotubes (CNT). Hybrid nonwovens consisting of PLA and GEL nanofibres (PLA/GEL), as well as CNT-modified PLA nanofibres with GEL nanofibres (PLA + CNT/GEL), in the form of mats, were manufactured using concurrent-electrospinning technique (co-ES). The ability of such hybrid structures as potential scaffolds for tissue engineering was studied. Both types of hybrid samples and one-component PLA and CNTs-modified PLA mats were investigated using scanning electron microscopy (SEM), water contact angle measurements, and biological and mechanical tests. The morphology, microstructure, and selected properties of the materials were analyzed. Biocompatibility and bioactivity in contact with normal human osteoblasts (NHOst) were studied. The coelectrospun PLA and GEL nanofibres retained their structures in hybrid samples. Both types of hybrid nonwovens were not cytotoxic and showed better osteoinductivity in comparison to scaffolds made from pure PLA. These samples also showed significantly reduced hydrophobicity compared to one-component PLA nonwovens. The CNT-contained PLA nanofibres improved mechanical properties of hybrid samples and such a 3D system appears to be interesting for potential application as a tissue engineering scaffold.
\end{abstract}

\section{Introduction}

The wide range of applications of fibrous structures obtained via electrospinning, including analytical chemistry, environmental protection, electrochemistry, industry, medicine, or everyday life products [1-3], makes this technique both versatile and prospective in the manufacture of high performance nanofibres. Considering the range of fibre diameters (i.e., several $\mu \mathrm{m}$ to $10 \mathrm{~s} \mathrm{~nm} \mathrm{[4])} \mathrm{possible} \mathrm{to} \mathrm{be} \mathrm{obtained} \mathrm{by} \mathrm{ES,} \mathrm{this}$ technique has found interest in specific tissue engineering applications. Furthermore, its simplicity facilitates the introduction and use of electrospun nanofibres.

Bearing in mind potential and current applications of the fibres obtained via ES [5-8] in regenerative medicine and tissue engineering, the choice of PLA as a well-known and biocompatible biomaterial [9] seems reasonable. Many PLA-based biomaterials in fibrous form including pure PLA fibres [10-12] and composite structures [13-15], obtained by sequential $[16,17]$ or blend ES $[18,19]$, have already been studied. Numerous works have already proven the beneficial role of PLA structures in enhancing tissue formation and regeneration [20-22]. Considering the similarities between the fibres obtained via ES and the extracellular matrix, structures manufactured by the ES technique provide promising materials for tissue engineering scaffolds, especially to regenerate bone tissue [5-7], cartilage tissue [ $8,23,24]$, skeletal joints between them [25], or neural tissue [26-28]. Fibrous structures are considered to be applied to regenerate bone tissue, in the case 
of small bone defects occurring from illnesses, injuries, or tumour resections. Since the gold standard in dealing with such defects, that is, autograft, has many drawbacks $[6,29]$, every alternative solution is highly welcome in the medical community.

The composite structure of PLA and GEL has been proven to enhance PLA biocompatibility and facilitate its degradation [18]. GEL is also known to effectively reduce the hydrophobicity of the substrate surface and can be the source of the amino acid sequence (RGD) enhancing cellular adhesion in in vitro studies [30].

When compared to collagen, a commonly used material in tissue engineering $[14,15]$, GEL manifests similar properties, but its price is much lower [31]. PLA/GEL fibrous materials may be used in guided cartilage regeneration as well. Gradient structures [32-34] of such a composition can be applied in skeletal junction scaffolds. The sequential [16, 17] and blend electrospinning $[18,19]$ of PLA and GEL have already been described.

As opposed to the aforementioned techniques, the coES process enables one to manufacture simultaneously two different polymer-based nanofibrous/microfibrous scaffolds. This technique has never been applied to manufacture PLA/GEL fibrous structures. In the search of tissue engineering, hybrid systems seem to be interesting solution to manufacture multifunctional scaffolds.

The purpose of the study was to manufacture PLA-based nanofibrous nonwovens that were modified using two types of modifiers, namely, GEL-based nanofibres and CNT. We wanted to verify if the GEL fibrous component affects the biocompatibility and hydrophobicity of the resulting PLA/GEL hybrid structure obtained by means of co-ES technique. So far, such a research related to the hybrid structure consisting of two fibrous components has not yet been made. Most of studies investigated PLA/GEL composite fibrous structures in the form of blends $[18,19]$. Unlike so far manufactured PLA and GEL scaffolds, either sequentially or from blends, our mats (nonwovens) were cospun and consisted of two independent fibrous components. The sequential method produces a layered structure, while fibres electrospun from the blends create mats composed of one type of composite fibres/nanofibres. The purpose of the work was also to investigate whether the co-ES process involves the interaction of both polymers during nanofibres forming, which may alter the properties of the base component, that is, PLA. The CNT component was used as a nanomodifier of the PLA nanofibres, to determine its impact on the biological and mechanical properties of the hybrid substrate. Two kinds of hybrid mats were manufactured, namely, PLA/GEL and PLA + CNT/GEL and for comparison one-component- (PLA-) based mats and PLA + CNT-based mats. The potential of such hybrid fibrous materials was discussed in terms of their use as scaffolds in tissue engineering.

The morphology of manufactured fibrous samples was characterised using scanning electron microscopy (SEM). Water contact angle measurements and mechanical and biological tests were used to compare the samples properties, and their usefulness as scaffolds for osteoblastic cells culture was discussed. Cell culture with human osteoblasts and the following in vitro tests to estimate the biocompatibility and bioactivity of the electrospun constructs were studied.

We used CNTs to modify PLA-based nanofibres to form nanocomposite fibres, as recent works have demonstrated numerous potential advantages of using carbon nanotubes over traditional materials for tissue-engineered constructs. Multiwalled carbon nanotubes (MWCNTs) have the ability to promote stem cells' differentiation towards bone cells and enhance bone formation [35-37]. Due to their nanometer scale size, with a very high strength to weight ratio, they are very attractive as a nanoadditive to improve mechanical properties of polymers, including PLA fibres [38-40]. Moreover, CNT have been proven to modify electrical properties of the fibrous structures obtained via ES [24, 38, 40]. This property is important when stimulating bone tissue formation [41]. Carbon nanotubes promote neuron cell formation [42], which could be used when designing scaffolds for neural tissue regeneration [43-45].

\section{Material and Methods}

2.1. Preparation of the Scaffolds. To obtain the hybrid nanofibre structure, two different polymers were used: poly(lactic acid), PLA (Ingeo ${ }^{\mathrm{TM}}$ Biopolymer 3251D, NatureWorks, LLC, USA, $M_{w}$ 90,000-120,000 g/mol), and gelatin, GEL (Avantor Performance Materials Poland S.A., Poland, $\left.M_{w} 40,000-100,000 \mathrm{~g} / \mathrm{mol}\right)$. The solution of PLA (15\% wt./v.) was prepared in dichloromethane, DCM (Avantor Performance Materials Poland S.A., Poland), and N,N-dimethylformamide, DMF (Avantor Performance Materials Poland S.A., Poland) (3: $1 \mathrm{wt}$. ratio). The $20 \%$ wt./v. GEL solution was prepared in concentrated (99.5-99.9\%) acetic acid (Avantor Performance Materials Poland S.A., Poland). The solutions were homogenised using a magnetic stirrer $(50 \mathrm{rpm})$ and heated at $35^{\circ} \mathrm{C}$ for $24 \mathrm{~h}$.

The PLA solution was further functionalised with multiwalled carbon nanotubes, CNTs (Nanostructured and Amorphous Materials Inc., USA; catalogue number 1213NMGS), at the concentration of $1 \%$ (wt.) with respect to the PLA content. CNTs were used in the form of suspension in the $\operatorname{DMF}(0.03 \mathrm{~g} / \mathrm{ml})$. CNTs were previously functionalised in the composition of inorganic acids, according to the procedure described in [46]. This modification introduced carbonyl and carboxyl groups to the surface of the CNTs, enabling their stable dispersion in the DMF. An adequate amount of the modifier was added to the previously prepared PLA solution and was stirred under gentle heating for $24 \mathrm{~h}$. Prior to use, the suspension containing CNT was additionally homogenised in an ultrasonic washer Sonic-0.5 (80 W; Polsonic Sp.J., Poland) for one hour.

The electrospinning (ES) process of the PLA and PLA + CNT fibres was conducted under processing parameters as follows: voltage $12 \mathrm{kV}$, needle inner diameter $0.9 \mathrm{~mm}$, needle-to-collector distance $3 \mathrm{~cm}$, collector rotation speed $100 \mathrm{rpm}$, flow rate $0.1 \mathrm{ml} / \mathrm{h}$, and deposition time $30 \mathrm{~min}$. The electrospun fibres were collected on the rotating mandrel covered with aluminium foil, from which they were separated prior to characterisation. The concurrent-electrospinning (co-ES) process of the PLA/GEL hybrid material was carried 
out using the same experimental setup. The processing parameters were the same as for the ES process. Both needles used had an inner diameter of $0.9 \mathrm{~mm}$ and were placed $3 \mathrm{~cm}$ from the collector. The deposition time was $30 \mathrm{~min}$ as well, the flow rate $0.1 \mathrm{ml} / \mathrm{h}$.

In the first stage of our work ES processing, parameters (applied voltage, needle-to-collector distance, needle inner diameter, concentration of the polymer in solution, and composition of solvent used) were evaluated for one-component materials, PLA and GEL separately. The results of these preliminary experiments are not included in this paper. The specified processing parameters were subsequently applied during co-ES process and ES process of PLA + CNTs. The dosage of polymer solutions was controlled using syringe infusion pumps. The flow rate of two solutions was the same; thus their volume ratio was $1: 1$. The concentrations of the polymer solutions used were different (15\% wt/v PLA and 20\% wt/v GEL), the mass ratio of PLA : GEL was approx. 1:1. Four types of samples were prepared for further study. Onecomponent mats have been labelled as PLA and PLA + CNT and hybrid mats as PLA/GEL and PLA + CNT/GEL.

2.2. Characterisation of the Scaffolds. The morphology of the fibres and the microstructure of the fibrous mats were studied by the scanning electron microscope (SEM: Nova NanoSEM 200; FEI Company, USA). The obtained images were analyzed using the ImageJ, version $1.50 \mathrm{~b}$ software, to determine the fibres' diameters. Using the segmental method, we calculated the overall porosity of the materials. The surface chemical properties were estimated using a static water drop-material contact angle $(\theta)$ measurements (DSA10; Kruss, Germany) that enable evaluating the wettability of the nonwovens. The presented wettability estimations were calculated as average of 30 measurements accompanied with SD value. The molecular structure of the polymer fibrous samples with carbon nanotubes was analyzed by FTIR method. Measurements were performed by Fourier Transform Infrared spectroscopy using Tensor 27 spectrometer (Bruker Optics, USA), equipped with the software OPUS 7.2. FTIR measurements were performed in single reflection ATR mode using diamond crystal MIRacle (PIKE Technologies, USA), without any preceding sample preparation. Samples of diameters $2 \times 2 \mathrm{~cm}$ were cut from the collected nonwoven mats and placed directly in ATR equipment. Each spectrum was registered after $128 \mathrm{scans}$ with resolution $4 \mathrm{~cm}^{-1}$. Mechanical testing of the fibrous mats was carried out on the universal testing machine Zwick 1435 (Zwick Roell, Germany) with load cell $5 \mathrm{kN}$. Samples in the form of stripes $(4 \times 0.5 \mathrm{~cm})$ were gripped (placed $24 \mathrm{~mm}$ apart) and elongated at a speed of $5 \mathrm{~mm} / \mathrm{min}$ until failure occurred. Tensile strength, $R_{m}$, and Young's modulus, $E$, were calculated from the obtained strain-elongation curves. For each type of fibrous sample, five individual measurements were made.

2.3. Cell Culture Experiments. In vitro experiments were performed using commercially available normal human osteoblasts, NHOst (Lonza, USA), and included proliferation, cytotoxicity, and mineralization tests. Prior to biological testing, samples of the nonwovens in the form of discs $(12 \mathrm{~mm}$ in diameter) were washed in $70 \%$ ethanol, dried in air at room temperature, and sterilized with a plasma technique $\left(40^{\circ} \mathrm{C}\right.$, $\mathrm{H}_{2} \mathrm{O}_{2}$ ), Sterrad 120, ASP, Johnson \& Johnson, USA.

NHOst were routinely grown in $75 \mathrm{ml}$ flasks in Osteoblast Growth Medium OGM, BulletKit (Lonza, USA), containing $10 \%$ FBS, $0.1 \%$ ascorbic acid, and 0.1\% GA-1000 (Gentamicin Sulfate and Amphotericin-B) in a 5\% CO2 and 95\% air atmosphere at $37^{\circ} \mathrm{C}$. Medium was changed every 2-3 days and the cell culture was passaged when $70 \%$ confluent cell monolayer was developed. After the 4th passage, the monolayer was brought into suspension with $0.5 \%$ trypsin plus EDTA (HyClone, USA). Following trypsinization, the cells were washed by centrifugation at $400 \mathrm{~g}$ for $5 \mathrm{~min}$ and resuspended in fresh full culture medium to a concentration of $1.5 \times 10^{4}$ cells $/ \mathrm{ml}$. Next, $1 \mathrm{ml}$ of cell suspension was added to each well of 48-well plates (Nunclon, Denmark) containing sterile biomaterials hold by polycarbonate inserts (Scaffdex, Finland) to prevent from floating. Cultures were performed in standard conditions for 3 and 7 days for the proliferation and cytotoxicity tests and for 7, 14, and 21 days for the mineralization assays. In the case of samples cultured for the mineralization tests, the differentiating factors (OGM Differentiation SingleQuot Kit, Lonza, USA) were added to the medium. The medium with pure PLA nonwoven (mat) served as a control sample (PLA). Biocompatibility of this material has been confirmed in previous studies of the authors [24].

The cells' viability and the cytotoxicity of the materials were determined by ToxiLight ${ }^{\mathrm{TM}}$ BioAssay kit and ToxiLight $^{\mathrm{TM}}$ 100\% Lysis Reagent Set (Lonza, USA). The ToxiLight BioAssay Kit was used to measure toxicity in cell culture supernatant. The kit quantitatively measures the release of adenylate kinase (AK) from damaged cells. The ToxiLight $100 \%$ lysis reagent used with the ToxiLight BioAssay Kit provides a total AK control value proportional to the total cell number (proliferation). The cytotoxicity and cells' proliferation were determined by luminescence measurements with the aid of POLARstar Omega microplate reader (BMG Labtech, Germany) and expressed in relative luminescence units (RLUs). The medium with pure PLA nonwovens served as a control sample (PLA). The cytotoxicity effect was performed as a percentage related to the total number of cells grown on biomaterials.

The mineralization process was evaluated using ALP assay (Sigma-Aldrich, Germany) and OsteoImage test (Lonza, USA) in order to estimate the level of cells' differentiation and osteoconductive properties of fibrous samples. These parameters were expressed in relative fluorescence units (RFUs) proportional to the ALP activity and concentration of hydroxyapatite (HA), respectively.

The alkaline phosphatase (ALP) activity was measured using 4-methylumbelliferyl phosphate (4-MUP). ALP cleaves the phosphate group of the nonfluorescent 4-MUP substrate into the soluble highly fluorescent substance methylumbelliferone (4-MU). After 7, 14, and 21 days of culture, cells were washed with Tris buffer $\mathrm{pH} \mathrm{8,4}$ and frozen. The cell cultures were lysed by three cycles of freeze-thawing, and such obtained cell homogenates were assayed for 


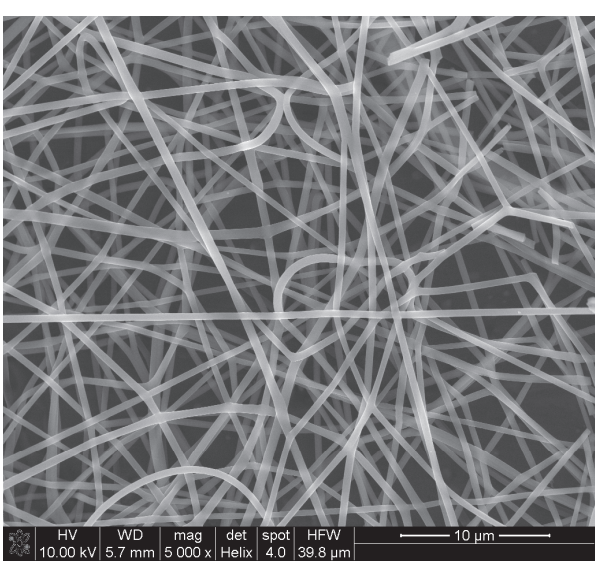

(a)

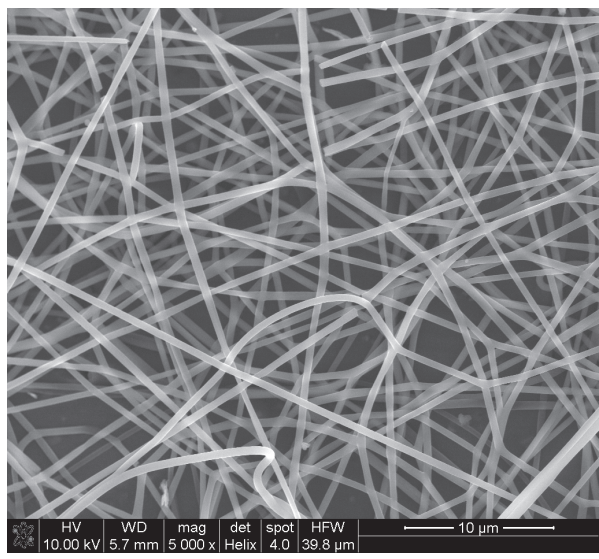

(c)

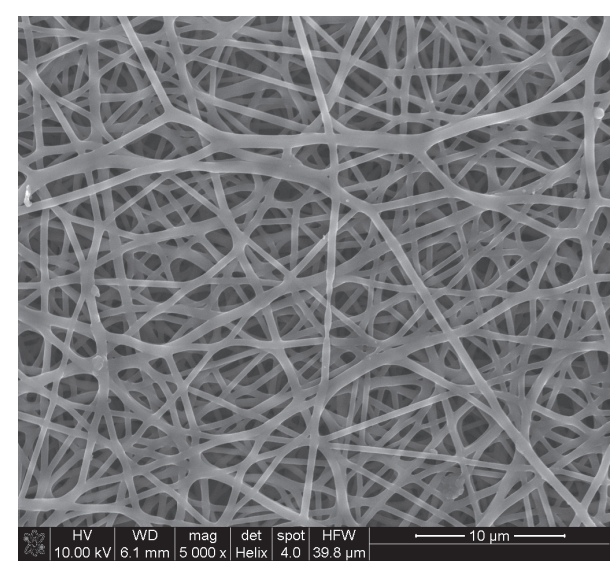

(b)

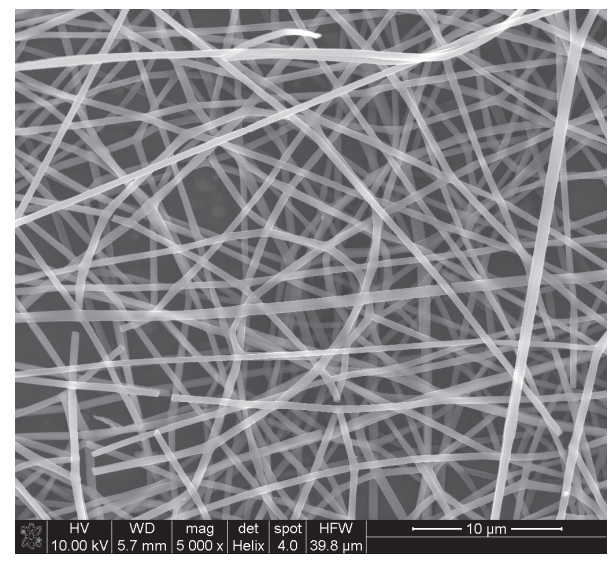

(d)

Figure 1: SEM images of fibrous scaffolds: (a) PLA, (b) PLA/GEL, (c) PLA + CNT/GEL, and (d) PLA + CNT.

ALP activity. Cell lysates in triplicate were transferred to OptiPlate-96 microplate (PerkinElmer, USA) and incubated for $1 \mathrm{~h}$ with an equal volume of 4-MUP Liquide Substrate System (Sigma-Aldrich, USA) solution. Fluorescence was determined at $360 / 450 \mathrm{~nm}$ (excitation/emission wavelengths) using POLARstar Omega microplate reader.

Differentiation of osteoblasts manifested in hydroxyapatite formation was assessed with OsteoImage Mineralization Assay (Lonza, USA). Fixed cells were stained with the bone nodule specific fluorescent reagent and washed with buffer. Fluorescence proportional to the amount of HA present in the culture was measured at 492/520 nm using POLARstar Omega reader.

For evaluation of the cells' morphology and their attachment to the fibrous samples the cell cultures were stained with 0,01\% acridine orange (AO) solution (Sigma-Aldrich, Germany) for $1 \mathrm{~min}$, washed in PBS, and observed under the fluorescence microscope Olympus CX41 (Japan). Photographic documentation was made by E-520 camera (Olympus, Japan).

Tests were repeated four times for all the samples and the reference PLA sample; the presented results are their mean values \pm standard error. For comparison between the means, Student's $t$-test with a $p$ value of 0.05 was used to measure statistical significance between each sample and control
(PLA), while one-way analysis (ANOVA) for assessing the differences between all samples with the Bonferroni post hot test was applied.

\section{Results and Discussion}

SEM images of the materials manufactured are presented in Figure 1. All the electrospun fibres were well formed, beadless, and created uniform mats. The overall porosity of the fibrous mats was very high, ranging within $0.88-0.93$ (Table 1 ).

Since biomaterials for tissue engineering purposes should have high porosities enabling cell infiltration during the culture and after implantation [47], the data obtained are favourable towards such an application. The average diameter of PLA fibres is high (Table 1), which was caused by the selected ES parameters. Our preliminary experiments showed that the most significant factor influencing fibres diameters was the inner diameter of the needle used. Smaller needles generated smaller diameters of the fibres, but with lower deposition rate and lower yield (thicker nonwovens). Because we wanted to further analyze the obtained fibrous mats, including mechanical and biological testing, we decided to obtain thicker materials with slightly higher fibre's diameter. The diameters of PLA fibres modified with 
TABLE 1: Characterisation of fibrous mats.

\begin{tabular}{|c|c|c|c|c|c|}
\hline Type & $\begin{array}{c}\text { Fibre } \\
\text { diameter, } d \\
(\mathrm{~nm})\end{array}$ & Material porosity, $p$ & $\begin{array}{c}\text { Wettability, } \\
\theta\left({ }^{\circ}\right)\end{array}$ & $\begin{array}{c}\text { Tensile } \\
\text { strength, } R_{m} \\
(\mathrm{MPa})\end{array}$ & $\begin{array}{l}\text { Young's } \\
\text { modulus, } E \\
(\mathrm{MPa})\end{array}$ \\
\hline PLA & $1029 \pm 36$ & $0.93 \pm 0.01$ & $113.3 \pm 1.0$ & $10.6 \pm 0.4$ & $686 \pm 42$ \\
\hline PLA/GEL & $400-1250^{*}$ & $0.88 \pm 0.01$ & $53.2 \pm 1.9$ & $4.1 \pm 0.6$ & $459 \pm 105$ \\
\hline $\mathrm{PLA}+\mathrm{CNT}$ & $306 \pm 17$ & $0.89 \pm 0.01$ & $108.3 \pm 1.4$ & $16.3 \pm 2.0$ & $1054 \pm 112$ \\
\hline $\mathrm{PLA}+\mathrm{CNT} / \mathrm{GEL}$ & $300-770^{*}$ & $0.87^{*}$ & $51.4 \pm 1.4$ & $12.3 \pm 1.9$ & $898 \pm 91$ \\
\hline
\end{tabular}

${ }^{*}$ Two-component fibre distribution.

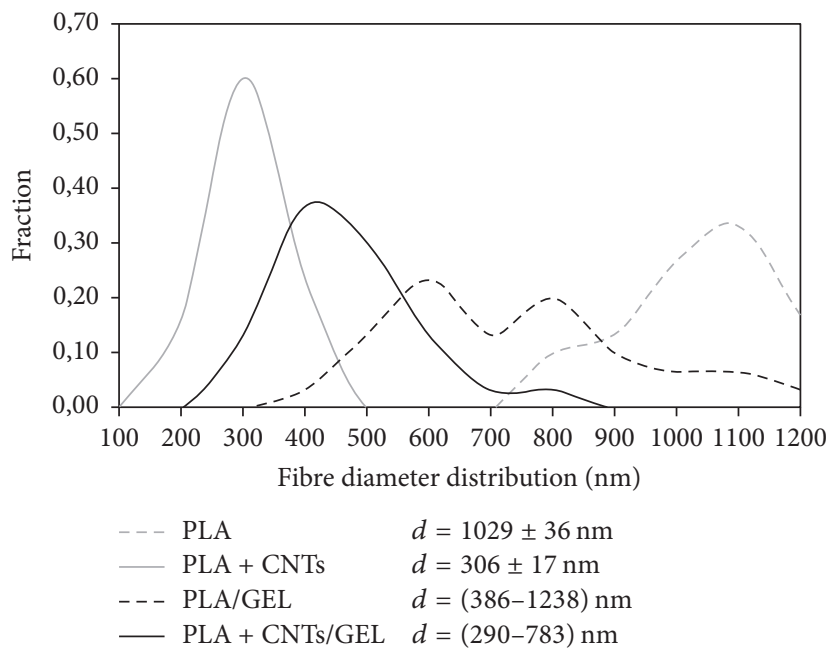

FIgURE 2: Distribution of fibre diameters in fibrous scaffolds.

CNT decreased significantly (Table 1). The addition of CNT increased the electrical conductivity of the PLA solution, resulting in favourable jets' splitting in the electrical field and smaller fibre diameters as compared to PLA fibres. Nonwovens were well formed, uniform, and defectless. Because CNTs were incorporated into the polymer solution in the form of stable suspension in DMF (a component of PLA solution), their full dispersion in the PLA solution facilitated forming uniform nanofibres. The PLA + CNT fibres were found to be the thinnest of all materials analyzed.

Figure 2 presents the distribution of fibre diameters in the manufactured scaffolds. As can be seen in the histograms, in the case of the hybrid PLA/GEL scaffolds, the range of diameters in the material is very wide, varying from 400 to $1250 \mathrm{~nm}$. Thicker fibres can be identified as PLA, compared to the average value of $1029 \mathrm{~nm}$ determined for one-component nonwovens. Thinner fibres are GEL with diameters of $350-800 \mathrm{~nm}$. In the case of the hybrid PLA + CNT/GEL scaffolds, the range of diameters in the material is narrowed as compared to PLA/GEL, varying from 300 to $770 \mathrm{~nm}$.

The presence of CNT in the polymer electrospinning suspensions significantly narrowed the distribution of fibre diameters and their average values as compared to pure PLA fibres. The co-ES of the composite material PLA/GEL revealed some interactions of the polymer streams in the electrical field. PLA and GEL streams emerging from the needle tip have charges of the same sign, resulting in their possible electrostatic repulsion. Polymer nanofibres were concurrently formed with lowered yield. To obtain a thicker layer of fibrous mat, the collecting mandrel was moved under an electric field several times. The obtained fibres within the mat were uniformly formed and bead-free.

Water drop contact angle measurements were performed in order to evaluate the chemical nature of the materials' surfaces. The calculated $\theta$ contact angle for PLA mats was about $113^{\circ}$, which is characteristic of hydrophobic materials $[19,48]$. PLA fibres modified with CNTs exhibit slightly smaller values, $\sim 108^{\circ}$. The water drop contact angle, $\theta$, recorded for two different modifiers, that is, GEL and CNTs, significantly differed. The hybrid compositions, PLA/GEL and PLA + CNT/GEL, are characterised by significantly lower $\theta\left(\sim 53^{\circ}\right.$ and $\sim 51^{\circ}$, resp.) compared to one-component PLA mats. Biomaterials used as scaffolds for tissue engineering purposes should be hydrophilic, because such a surface characteristic facilitates cells' seeding and culturing $[49,50]$. The obtained hybrid mats fulfil this condition, providing favourable conditions for cell culture in vitro. Thus, the fibrous modifier made of GEL nanofibres altered significantly surface characteristic of the hybrid samples.

The mechanical testing experiments revealed significant differences between the analyzed materials. PLA nonwoven exhibited much better mechanical properties $\left(R_{m} \sim 11 \mathrm{MPa}\right.$, $E \sim 690 \mathrm{MPa}$ ), in comparison with hybrid PLA/GEL samples $\left(R_{m} \sim 4 \mathrm{MPa}, E \sim 460 \mathrm{MPa}\right)$. It is worth noting, however, that the studied materials in the form of nonwovens are characterised by a very high porosity. The measured the strength and Young's modulus were calculated taking into account the samples cross section without their porosity. The addition of CNT into PLA fibres improved the mechanical properties (Table 1) of one-component sample (PLA + CNT), as well as the hybrid samples. The growth of Young's modulus of the hybrid scaffolds is a beneficial effect taking into consideration their possible applications in tissue engineering.

Figure 3 shows the FTIR spectra of electrospun nanofibrous samples. FTIR spectroscopy was used to investigate possible interaction of PLA with CNT and PLA with GEL in hybrid scaffolds. The FTIR spectra of PLA and CNTmodified PLA, that is, PLA + CNT, show the characteristic bands for PLA at $1748 \mathrm{~cm}^{-1}$ assigned to stretching vibration of $-\mathrm{C}=\mathrm{O}$ and at $1453 \mathrm{~cm}^{-1}$ associated with $\mathrm{CH}_{3}$ groups. The position of the bands associated with the presence of the nanotubes is indicated by arrows $\left(1380,1220 \mathrm{~cm}^{-1}\right)$. Due to a small concentration of CNT in the polymer (1 wt.\%), the 

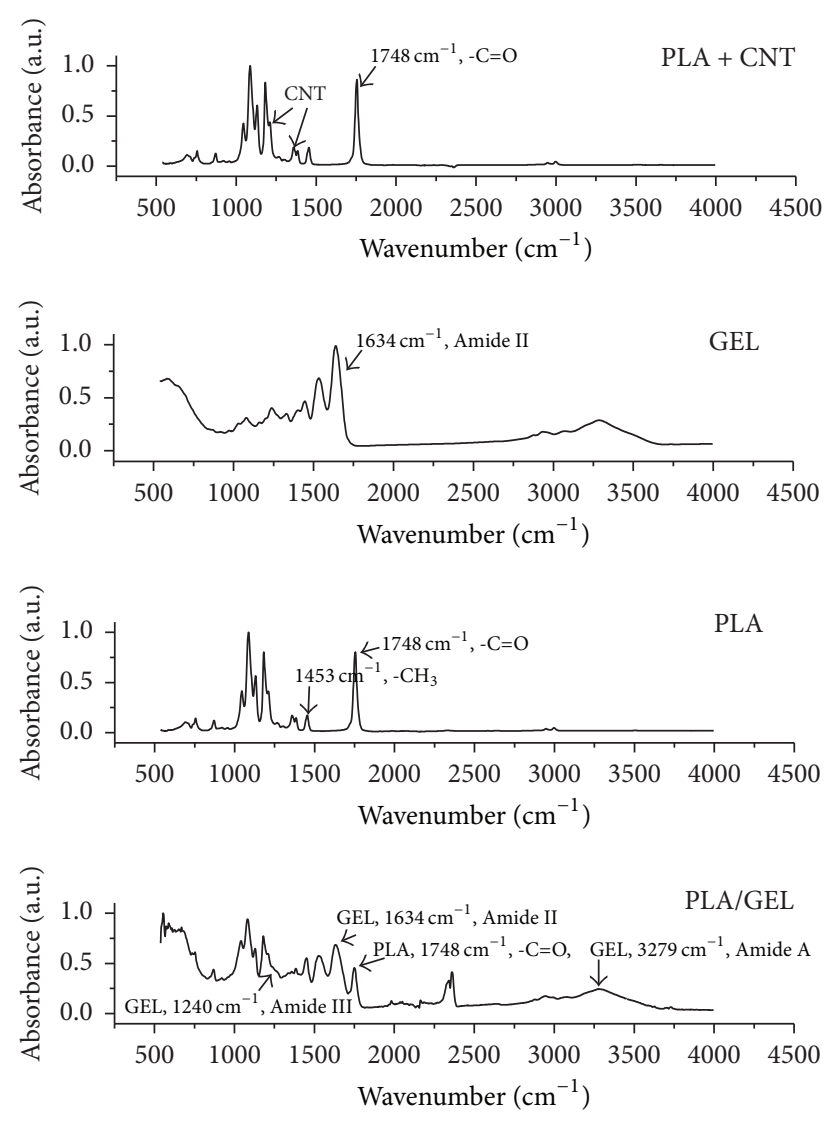

FIGURE 3: FTIR spectra of electrospun fibrous scaffolds.

comparison of both CNT-modified PLA spectra indicates that the presence of the nanotubes in the polymer matrix does not shift the position of the bands characteristic for pure PLA. A comparison between spectra of pure PLA and PLA/GEL showed that the bands assigned to PLA do not shift their wavenumbers in hybrid sample, which indicates that no chemical interaction between PLA and GEL took place during electrospinning process and their molecular structures are unchanged. Figure 3 shows a typical FTIR spectrum (PLA/GEL) composed of two overlapping spectra containing the bands characteristic for pure PLA and gelatin. It shows three major peak regions marked in Figure 3 as $3279 \mathrm{~cm}^{-1}$ assigned to the bonds of Amide A, $1634 \mathrm{~cm}^{-1}$ (Amides I and II), and at about $1240 \mathrm{~cm}^{-1}$ assigned to the Amide III.

Biological tests performed aimed to evaluate the samples' biocompatibility and bioactivity. The analysis of the NHOst's morphology showed that cells covered uniformly and densely the materials' surfaces (Figure 4).

Their shape was uniform and they were flattened, mostly well spread on the sample surface. Already after three days of incubation, numerous intercellular connections were observed, creating a dense cellular web. Such an image was observed especially for PLA + CNT sample (Figures 4(a) and $4(b)$ ), where cells forming a lot of contacts with each other and the substrate were well spread. Good cells adhesion to the surface is important factor in terms of further cellular functions, such as proliferation, secretion, and production of the extracellular matrix. NHOst morphology in contact both with PLA/GEL is similar to cells in contact with control (PLA). In the case of hybrid PLA/GEL and PLA + CNT/GEL samples, the cells additionally penetrated into the scaffolds' depth (Figures 5(a) and 5(b)). As is apparent from these microphotographs, on day 7 after seeding nanofibrous network, the cells placed inside the scaffolds can be found (Figure 5(a)). For a better cell visualization, the computer imposition of red colour on cells was applied (Figure 5(b)). Such images revealed that the analyzed nonwovens made from hybrid nanofibres, having a good porous interconnectivity between the nanofibres, seem to have a suitable $3 \mathrm{D}$ architecture for cell culturing.

Figure 6 compares the cells' viability cultured on nanofibrous samples manufactured from pure PLA (control) and modified with CNT and GEL. Cells viability in contact with nanofibrous scaffolds after 3 of culture was comparable to control, while it, after 7 days, was statistically lower $(p<0.05)$ in comparison with control. The cytotoxicity results of the fibrous samples compared to the control, PLA, are shown in Figure 7.

Cells cytotoxicity determined on day 3 after seeding was comparable for all samples. On day 7 after cells seeding, a significant decrease in cytotoxicity for all samples can be observed. A statistical difference was only observed between PLA + CNT/GEL and PLA/GEL. Although there are some differences between the samples, both biological tests indicate that all analyzed nonwovens were biocompatible.

The results of bioactivity tests are summarised in Figures 8 and 9. The mineralization process assessment showed statistical differences $(p<0.05)$ in the HA concentration between control (PLA) and PLA + CNT/GEL after 14 days and after 21 days between control and both hybrid scaffolds modified with GEL. The same dependencies between control and hybrid scaffolds were found in ALP activity.

After 21 days, both tests revealed statistically significant differences $(p<0.05)$ between the control and PLA/GEL and PLA + CNT samples (Figure 9). Moreover, the highest increase in ALP activity in the period between 14 days and 21 days, amounting to about $50 \%$, was noted for the PLA/GEL and PLA + CNT/GEL compared to $14.5 \%$ for control (PLA). Certainly, prolonging the culture would reveal more significant differences between the control and the hybrid and PLA + CNT samples. These results indicate that the hybrid nonwovens and PLA containing functionalised CNT display better osteoinductivity as compared to nonwovens made from pure PLA nanofibres.

Experiments conducted by numerous workers have shown that the degree and type of functionalisation strongly affects CNT cytotoxicity $[45,46,48]$. Here, the cells were incubated on electrospun nonwoven mats for a relatively short time; hence, some effects could not have been visible. It is probable that, during a longer cell culture, the PLA matrix could begin to degrade and release CNT, affecting the results of the tests performed.

Varying nanofibrous substrates were manufactured by the ES technique. An often-used tool in tissue engineering is cells scaffold, which constitutes a substitute for the extracellular 


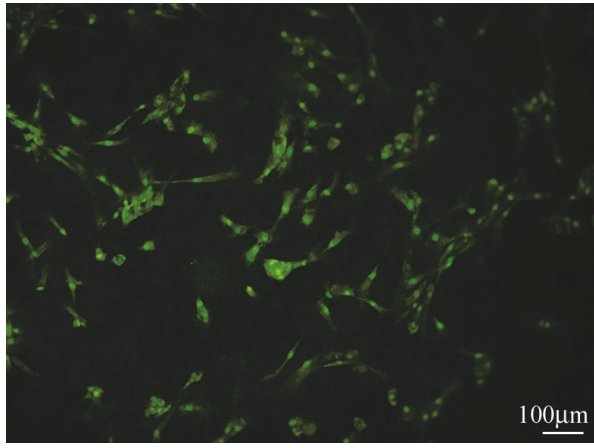

(1a)

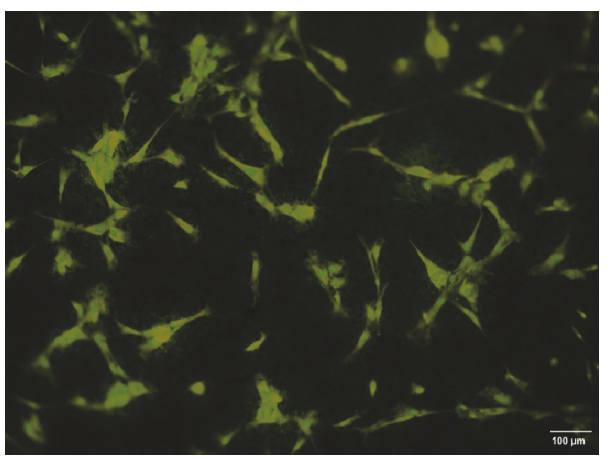

(2a)

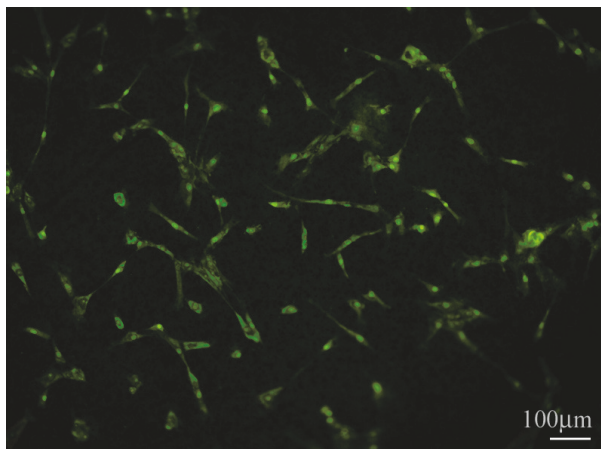

(3a)

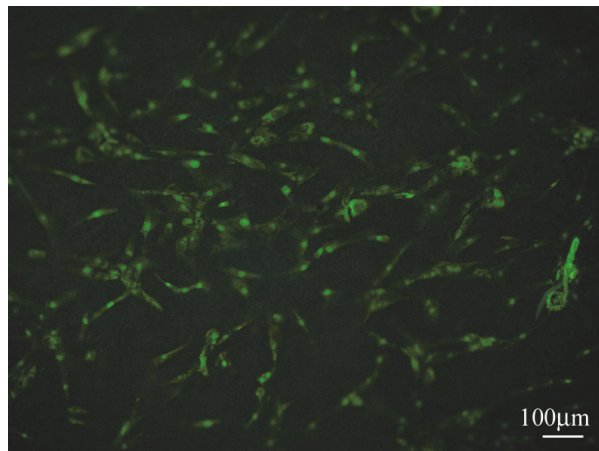

(4a)

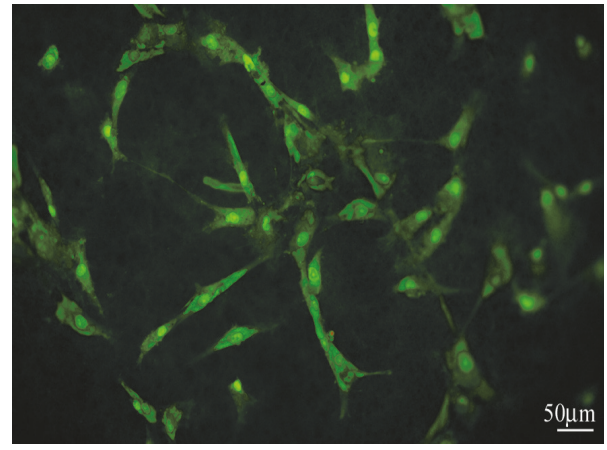

(1b)

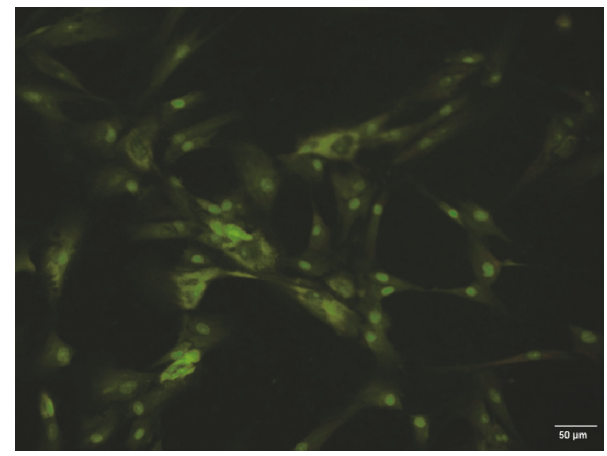

$(2 \mathrm{~b})$

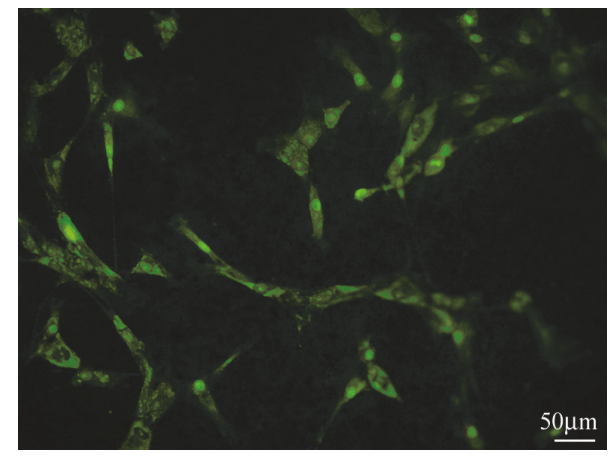

$(3 \mathrm{~b})$

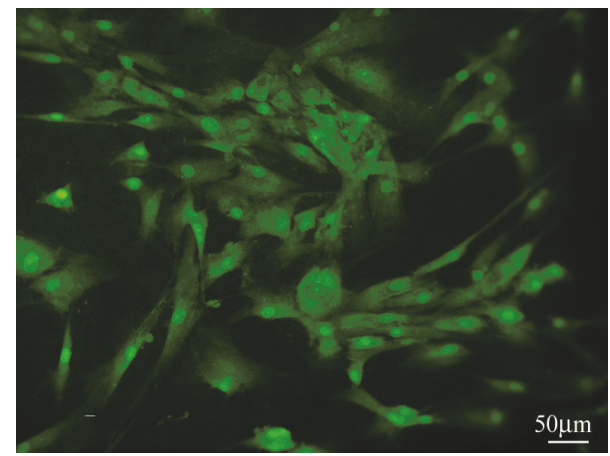

(4b)

Figure 4: Morphology of NHOst cultured for three days in contact with fibrous scaffolds: (1) PLA (control), (2) PLA/GEL, (3) PLA + CNT/GEL, and (4) PLA + CNT (magnified 10x (a) and 20x (b)). 


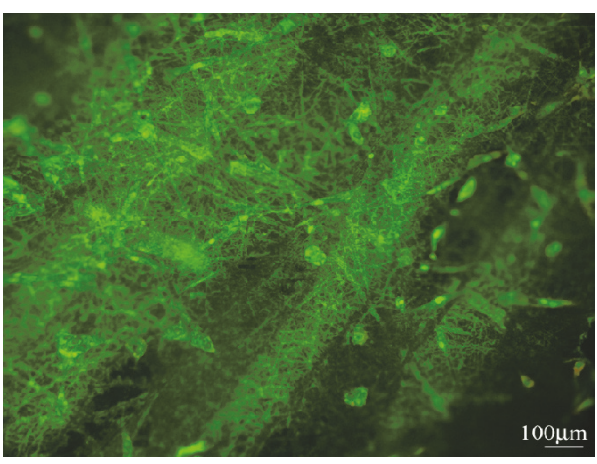

(a)

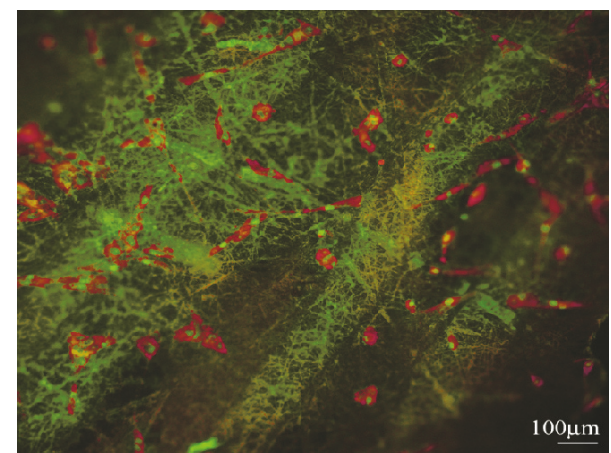

(b)

FIGURE 5: Morphology of NHOst inside PLA/GEL scaffold after 7 days of culture: (a) the original microphotograph from fluorescence microscope; (b) this microphotograph after photographic processing (mag. 10x).

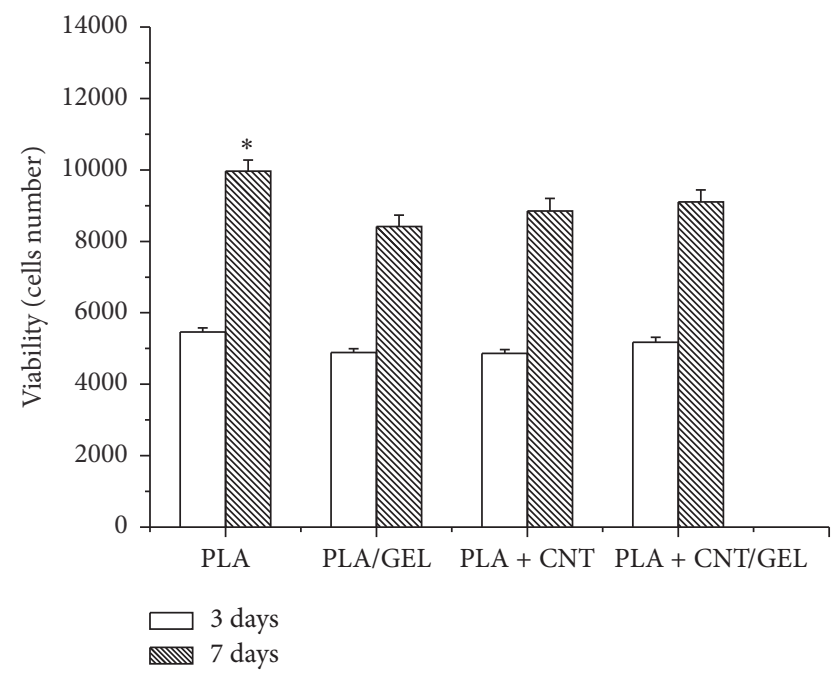

FIGURE 6: Cell viability of NHOst cultured in contact with fibrous scaffolds; *statistically significant (PLA) versus (PLA/GEL) and CNT-containing samples on day $7(p<0.05)$.

matrix (ECM). Such a natural structure is composed mainly of protein fibres (e.g., collagen and elastin), with diameters in the range of $10-100 \mathrm{~nm}$ and the nanometric adhesive proteins allowing for cell attachment [44]. The ECM microenvironment creates optimal conditions for intercellular interactions and influences the differentiation and cell functions. Nanofibre-based scaffolds are increasingly popular in tissue engineering as their architecture refers to a natural ECM and are used for preparing biomimetic scaffolds. Several studies have shown that the diameter of the fibres constructing cell scaffolds influences the differentiation of neural stem cells. The reduction in fibre diameter increases cell proliferation and differentiates their ingrowth into the scaffold space and reduces their aggregation [4].

The co-ES technique enables forming simultaneously two different nanofibre polymers. The modification of the polymer precursor of small quantities of nanofillers opens a range of new opportunities to obtain advanced nanofibrous

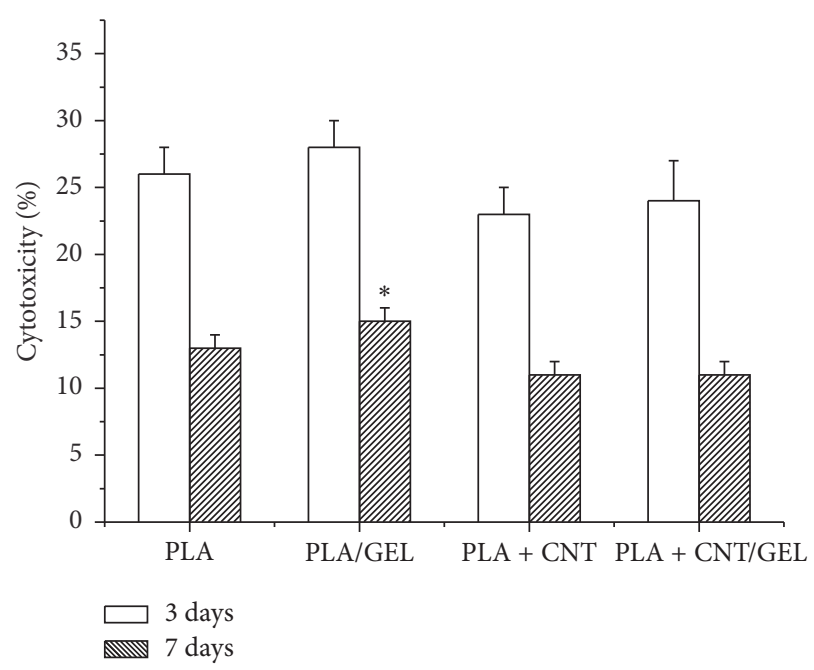

Figure 7: Cytotoxicity for NHOst cultured in contact with fibrous scaffolds; * statistically significant (PLA/GEL) versus (PLA $+\mathrm{CNT} / \mathrm{GEL})$ on day $7,(p<0.05)$.

composite scaffolds. It has already been proven that a composite biomaterial composed of PLA/PLA + CNT and GEL nanofibres retains the biocompatibility of the PLA, whereas the GEL constituent, depending on its content, may act as degradation moderator [16]. Its presence in the elaborated hybrid samples effectively reduced hydrophobicity of the substrate surface what was one of the aim of the study. PLA/PLA + CNT and GEL fibrous materials could also be used in guided cartilage regeneration, whereas gradient structures of such a composition can be applied in skeletal junction scaffolds.

The aim to modify the structure of the polymer nanofibre using the CNTs was to develop a substrate comprising the active substance in chondrogenesis. Several results confirm the hypothesis that the carbon component may act as chondrogenic material $[51,52]$. Carbon materials, including carbon fibres and carbon nanotubes, have been successfully used in the treatment of cartilage defects. In the experiments 


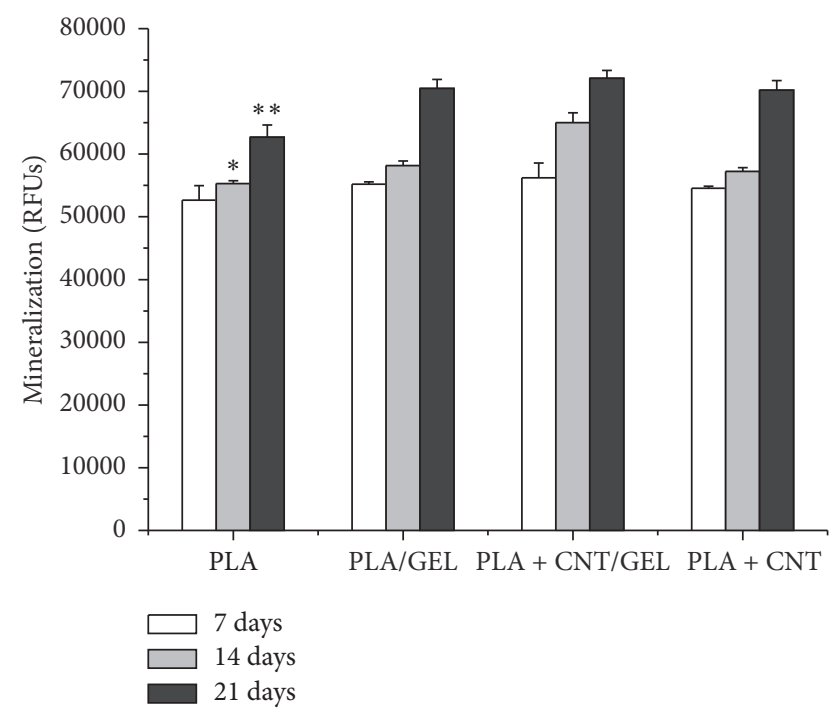

FIgURE 8: Mineralization progress of NHOst cultured in contact with fibrous scaffolds; ${ }^{*}$ statistically significant (PLA) versus (PLA/GEL) and (PLA + CNT/GEL) on day $14(p<0.05)$; ${ }^{* *}$ statistically significant (PLA) versus (PLA/GEL) and (PLA + CNT) on day $21(p<0.05)$.

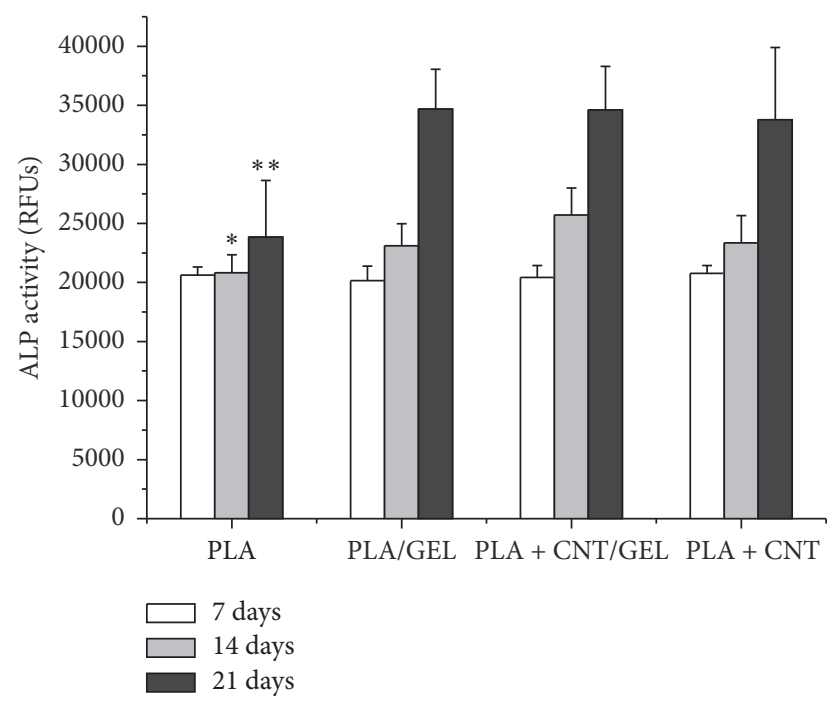

FIgURE 9: ALP activity in NHOst cells cultured in contact with fibrous scaffolds; * statistically significant (PLA) versus (PLA + CNT/GEL) on day $14,(p<0.05) ;{ }^{* *}$ statistically significant (PLA) versus (PLA/GEL), (PLA + CNT/GEL), and (PLA + CNT) on day $21(p<0.05)$.

conducted here, the CNT were added to functionalise polymer nanofibres and to modify their mechanical and biological properties. Comparative results of pure PLA and modified nanofibres have confirmed that the presence of CNT changes their mechanical characteristics and improves the strength and Young's modulus. PLA nanofibres are degraded in a biological environment and over time can be expected to expose the surface of $\mathrm{CNT}$ that can participate in the process of regeneration of tissue. The exposed CNT can induce regenerative processes, depending on the intended use, in bone, nervous, or cartilage tissue. In addition, polymeric fibrous scaffolds with a specific orientation of nanofibres may favour directional cell growth $[24,46]$. The biological test showed that the nanofibres containing the carbon nanotubes were not toxic. Their presence in PLA nanofibres also modifies the electrical properties. Electrical conductivity is an important property in tissue regeneration, that is, for nerve tissue engineering by stimulating neurite growth $[42,43]$. Various polymer nanofibres including PLA can be functionalised to make them electrically conductive to stimulate neurite elongation. For this purpose, PLA modified with CNTs and gelatin results in obtaining conductive hybrid nanofibres, supporting the proliferation and differentiation of NHOst.

Two different sources of polymer solutions enabled using a larger number of potential modifiers and can also be obtained in the further gradient structure with a controlled phase system. The 3-dimensional hybrid structures manufactured by electroforming developed here may provide scaffolds for repair of cartilage defects, able to replace the natural extracellular matrix, for bone tissue regeneration and for nerve tissue regeneration. It was found that by adding $1 \%$ wt CNT significant change in electrical properties can be obtained, that is, from dielectric properties of pure PLA to semiconducting material PLA + CNT [24]. Such fibrous 3D structures can also assure integrity and stability between a newly formed tissue and the host tissue. The results presented here also encourage further investigation of the combination of nanofibrous components, that is, by using PLA nanofibres modified with functionalised CNTs and GEL-based fibrous components.

\section{Conclusions}

The results of this study have demonstrated that hybrid PLA/GEL materials can be formed by the co-ES technique, and the obtained mats, due to their biocompatibility and physicochemical characteristics, can be considered in tissue engineering. Both simultaneously electrospun nanofibres retain their structures in the hybrid mats. The hybrid samples show significantly reduced hydrophobicity compared to onecomponent PLA mats. The water drop contact angle, $\theta$, of fibrous samples decreased from about $113^{\circ}$ for the PLA samples to $51^{\circ}$ for PLA + CNT/GEL. The mineralization process evaluated using ALP tests indicated that both hybrid nonwovens (PLA/GEL and PLA + CNT/GEL) showed better osteoinductivity in comparison to scaffolds made from pure PLA nanofibres. The results obtained for the hybrid scaffolds make such a fibrous combination more promising for osteoblastic cells culture. The modification of PLA nanofibres with CNT proved to be a relatively easy way for further improving their mechanical properties. The presence of CNT in the PLA fibrous component improved significantly mechanical properties of hybrid mats as compared to the PLA/GEL samples, in particular Young's modulus. Such a hybrid PLA + CNT/GEL system demonstrates pliable and biodegradable $3 \mathrm{D}$ scaffold with a highly porous structure. 


\section{Conflicts of Interest}

The authors declare that they have no conflicts of interest.

\section{Acknowledgments}

This work was supported by the National Science Center (Poland), Project no. 2013/11/N/ST8/01169, and by the Statute Fund of Laryngology Department, School of Medicine in Katowice, Medical University of Silesia (Katowice, Poland), KNW-1-125/N/5/0.

\section{References}

[1] S. Chigome and N. Torto, "A review of opportunities for electrospun nanofibers in analytical chemistry," Analytica Chimica Acta, vol. 706, no. 1, pp. 25-36, 2011.

[2] R. Balamurugan, S. Sundarrajan, and S. Ramakrishna, "Recent trends in nanofibrous membranes and their suitability for air and water filtrations," Membranes, vol. 1, no. 3, pp. 232-248, 2011.

[3] D. B. Khadka and D. T. Haynie, "Paclitaxel-loaded polymeric micelles based on poly( $\varepsilon$-caprolactone)-poly(ethylene glycol)poly ( $\varepsilon$-caprolactone) triblock copolymers: in vitro and in vivo evaluation," Nanomedicine: Nanotechnology, Biology and Medicine, vol. 8, no. 6, pp. 1242-1262, 2012.

[4] A. Frenot and I. S. Chronakis, "Polymer nanofibers assembled by electrospinning," Current Opinion in Colloid and Interface Science, vol. 8, no. 1-2, pp. 64-75, 2003.

[5] L. Zhang and T. J. Webster, "Nanotechnology and nanomaterials: promises for improved tissue regeneration," Nano Today, vol. 4, no. 1, pp. 66-80, 2009.

[6] M. M. Stevens, "Biomaterials for bone tissue engineering," Materials Today, vol. 11, no. 5, pp. 18-25, 2008.

[7] J. M. Holzwarth and P. X. Ma, "Biomimetic nanofibrous scaffolds for bone tissue engineering," Biomaterials, vol. 32, no. 36, pp. 9622-9629, 2011.

[8] W. J. Li, R. Tuli, C. Okafor et al., "A three-dimensional nanofibrous scaffold for cartilage tissue engineering using human mesenchymal stem cells," Biomaterials, vol. 26, no. 6, pp. 599609, 2005.

[9] D. Garlotta, "A literature review of poly(lactic acid)," Journal of Polymers and the Environment, vol. 9, no. 2, pp. 63-84, 2001.

[10] X. Zong, K. Kim, D. Fang, S. Ran, B. S. Hsiao, and B. $\mathrm{Chu}$, "Structure and process relationship of electrospun bioabsorbable nanofiber membranes," Polymer, vol. 43, no. 16, pp. 4403-4412, 2002.

[11] R. Inai, M. Kotaki, and S. Ramakrishna, "Structure and properties of electrospun PLLA single nanofibres," Nanotechnology, vol. 16, no. 2, pp. 208-213, 2005.

[12] L. D. Wright, R. T. Young, T. Andric, and J. W. Freeman, "Fabrication and mechanical characterization of 3D electrospun scaffolds for tissue engineering," Biomedical Materials, vol. 5, pp. 055-060, 2010.

[13] N. D. Luong, I. S. Moon, D. S. Lee, Y. K. Lee, and J. D. Nam, "Surface modification of poly(L-lactide) electrospun fibers with nanocrystal hydroxyapatite for engineered scaffold applications," Materials Science and Engineering: C, pp. 1242-1249, 2008.

[14] J. B. Chiu, C. Liu, B. S. Hsiao, B. Chu, and M. J. Hadjiargyrou, "Functionalization of poly(l-lactide) nanofibrous scaffolds with bioactive collagen molecules," Journal of Biomedical Materials Research Part A, vol. 83, pp. 1118-1127, 2007.

[15] S. Torres-Giner, J. V. Gimeno-Alcañiz, M. J. Ocio, and J. M. Lagaron, "Optimization of electrospun polylactide-based ultrathin fibers for osteoconductive bone scaffolds," Journal of Applied Polymer Science, vol. 122, no. 2, pp. 914-925, 2011.

[16] S. Wang, Y. Zhang, G. Yin, H. Wang, and Z. Dong, "Electrospun polylactide/silk fibroin-gelatin composite tubular scaffolds for small-diameter tissue engineering blood vessels," Journal of Applied Polymer Science, vol. 113, no. 4, pp. 2675-2682, 2009.

[17] G. B. Yin, Y. Z. Zhang, J. L. Wu, S. D. Wang, B. D. Shi, and Z. H. J. Dong, "Study on the electrospun Poly(lactic acid)/silk fibroingelatin composite nanofibrous scaffold for tissue engineering," Journal of Fiber Bioengineering and Informatics, vol. 2, pp. 182188, 2009.

[18] M. Z. Hu and C. E. Easterly, "A novel thermal electrochemical synthesis method for production of stable colloids of "naked" metal (Ag) nanocrystals," Materials Science and Engineering: C, vol. 29, no. 3, pp. 726-736, 2009.

[19] H. W. Kim, H. S. Yu, and H. H. J. Lee, "Nanofibrous matrices of poly(lactic acid) and gelatin polymeric blends for the improvement of cellular responses," Journal of Biomedical Materials Research Part A, vol. 87, pp. 25-32, 2008.

[20] W. Y. Ip, "Polylactide membranes and sponges in the treatment of segmental defects in rabbit radii," Injury, vol. 33, pp. B66-B70, 2001.

[21] A. Gerber, A. Gerber, and S. Gogolewski, "Reconstruction of large segmental defects in the sheep tibia using polylactide membranes. A clinical and radiographic report," Injury, vol. 33, no. 2, pp. 43-57, 2002.

[22] Z. Gugala and S. Gogolewski, "Healing of critical-size segmental bone defects in the sheep tibiae using bioresorbable polylactide membranes," Injury, vol. 33, no. 2, pp. 71-76, 2002.

[23] E. J. Levorson, P. R. Sreerekha, K. P. Chennazhi, F. K. Kasper, S. V. Nair, and A. G. Mikos, "Fabrication and characterization of multiscale electrospun scaffolds for cartilage regeneration," Biomedical Materials, vol. 8, no. 1, Article ID 014103, 2013.

[24] J. Markowski, A. Magiera, M. Lesiak, A. L. Sieron, J. Pilch, and S. Blazewicz, "Preparation and characterization of nanofibrous polymer scaffolds for cartilage tissue engineering," Journal of Nanomaterials, vol. 2015, Article ID 564087, 2015.

[25] P. A. Mouthuy, H. Ye, J. Triffitt, G. Oommen, and Z. Cui, "Physico-chemical characterization of functional electrospun scaffolds for bone and cartilage tissue engineering," Proceedings of the Institution of Mechanical Engineers, Part H: Journal of Engineering in Medicine, vol. 224, pp. 1401-1414, 2010.

[26] Y.-S. Lee and T. L. Arinzeh, "Electrospun nanofibrous materials for neural tissue engineering," Polymers, vol. 3, no. 1, pp. 413426, 2011.

[27] M. P. Prabhakaran, J. Venugopal, C. K. Chan, and S. Ramakrishna, "Surface modified electrospun nanofibrous scaffolds for nerve tissue engineering," Nanotechnology, vol. 19, no. 45, Article ID 455102, 2008.

[28] F. Yang, R. Murugan, S. Wang, and S. Ramakrishna, "Electrospinning of nano/micro scale poly(L-lactic acid) aligned fibers and their potential in neural tissue engineering," Biomaterials, vol. 26, no. 15, pp. 2603-2610, 2005.

[29] G. Stylios, T. Wan, and P. Giannoudis, "Present status and future potential of enhancing bone healing using nanotechnology," Injury, vol. 38, no. 1, pp. S63-S74, 2007. 
[30] N. Davidenko, CF. Schuster, DV. Bax, R. W. Farndale, S. Hamaia, and S. M. Best, "Evaluation of cell binding to collagen and gelatin: a study of the effect of 2D and 3D architecture and surface chemistry," Journal of Materials Science: Materials in Medicine, vol. 27, pp. 148-159, 2016.

[31] J. Ratanavaraporn, S. Damrongsakkul, N. Banaprasert, and T. Kanokpanont, JOM: Journal of the Minerals, metals, and Materials Society, vol. 16, pp. 31-36, 2006.

[32] M. R. Ladd, S. J. Lee, J. D. Stitzel, A. Atala, and J. J. Yoo, "Coelectrospun dual scaffolding system with potential for muscletendon junction tissue engineering," Biomaterials, vol. 32, no. 6, pp. 1549-1559, 2011.

[33] Z. M. Huanga, Y. Z. Zhang, M. Kotakic, and S. Ramakrishna, "A review on polymer nanofibers by electrospinning and their applications in nanocomposites," Composites Science and Technology, vol. 63, pp. 2223-2253, 2003.

[34] H. G. Sundararaghavan and J. A. Burdick, "Gradients with depth in electrospun fibrous scaffolds for directed cell behavior," Biomacromolecules, vol. 12, no. 6, pp. 2344-2350, 2011.

[35] A. J. Salgado, O. P. Coutinho, and R. L. Reis, "Bone tissue engineering: state of the art and future trends," Macromolecular Bioscience, vol. 4, pp. 743-765, 2014.

[36] S. Shao, S. Zhou, L. Li et al., "Osteoblast function on electrically conductive electrospun PLA/MWCNTs nanofibers," Biomaterials, vol. 32, no. 11, pp. 2821-2833, 2011.

[37] H. Haniu, T. Tsukahara, . Matsuda et al., "DJ-1 as a potential biomarker for the development of biocompatible multiwalled carbon nanotubes," International Journal of Nanomedicine, Article ID 343747, p. 2689, 2012.

[38] D. Lahiri, F. Rouzaud, S. Namin et al., "Carbon nanotube reinforced polylactide-caprolactone copolymer: mechanical strengthening and interaction with human osteoblasts in vitro," ACS Applied Materials and Interfaces, vol. 1, no. 11, pp. 24702476, 2009.

[39] T. Yang, D. Wu, L. Lu, W. Zhou, and M. Zhang, "Electrospinning of polylactide and its composites with carbon nanotubes," Polymer Composites, vol. 32, no. 8, pp. 1280-1288, 2011.

[40] P. Pötschke, A. R. Bhattacharyya, A. Janke et al., "Melt mixing as method to disperse carbon nanotubes into thermoplastic polymers," Fullerenes Nanotubes and Carbon Nanostructures, vol. 13, no. supplement 1, pp. 211-224, 2005.

[41] L. Yeo and J. R. Friend, "Electrospinning carbon nanotube polymer composite nanofibers," Journal of Experimental Nanoscience, vol. 1, pp. 177-209, 2006.

[42] B. Ercan and T. J. Webster, "The effect of biphasic electrical stimulation on osteoblast function at anodized nanotubular titanium surfaces," Biomaterials, vol. 31, no. 13, pp. 3684-3693, 2010.

[43] T.-I. Chao, S. Xiang, C.-S. Chen et al., "Carbon nanotubes promote neuron differentiation from human embryonic stem cells," Biochemical and Biophysical Research Communications, vol. 384, no. 4, pp. 426-430, 2009.

[44] M. A. Shokrgozar, F. Mottaghitalab, V. Mottaghitalab, and M. Farokhi, "Fabrication of porous chitosan/poly(vinyl alcohol) reinforced single-walled carbon nanotube nanocomposites for neural tissue engineering," Journal of Biomedical Nanotechnology, vol. 7, no. 2, pp. 276-284, 2011.

[45] B. S. Harrison and A. Atala, "Carbon nanotube applications for tissue engineering," Biomaterials, vol. 28, no. 2, pp. 344-353, 2007.
[46] A. Fraczek, E. Menaszek, C. Paluszkiewicz, and M. Blazewicz, "Comparative in vivo biocompatibility study of single- and multi-wall carbon nanotubes," Acta Biomaterialia, vol. 4, no. 6, pp. 1593-1602, 2008.

[47] S. Soliman, S. Pagliari, A. Rinaldi et al., "Multiscale threedimensional scaffolds for soft tissue engineering via multimodal electrospinning," Acta Biomaterialia, vol. 6, no. 4, pp. 1227-1237, 2010.

[48] A. Fraczek-Szczypta, E. Menaszek, and S. Blazewicz, "Some observations on carbon nanotubes susceptibility to cell phagocytosis," Journal of Nanomaterials, vol. 2011, Article ID 473516, 8 pages, 2011.

[49] X. Zonga, H. Bienc, C. Y. Chungc, L. Yinc, D. Fangb, and B. S. Hsiao, "Electrospun fine-textured scaffolds for heart tissue constructs," Biomaterials, vol. 26, pp. 5330-5338, 2005.

[50] Y. Z. Zhang, B. Su, J. Venugopal, S. Ramakrishna, and C. T. Lim, "Biomimetic and bioactive nanofibrous scaffolds from electrospun composite nanofibers," International Journal of Nanomedicine, vol. 2, pp. 623-638, 2007.

[51] E. Dlugon, W. Simka, A. Fraczek-Szczypta et al., "Carbon nanotube-based coatings on titanium," Bulletin of Materials Science, vol. 38, no. 5, pp. 1339-1344, 2015.

[52] A. Abarrategi, M. C. Gutiérrez, C. Moreno-Vicente et al., "Multiwall carbon nanotube scaffolds for tissue engineering purposes," Biomaterials, vol. 29, no. 1, pp. 94-102, 2008. 

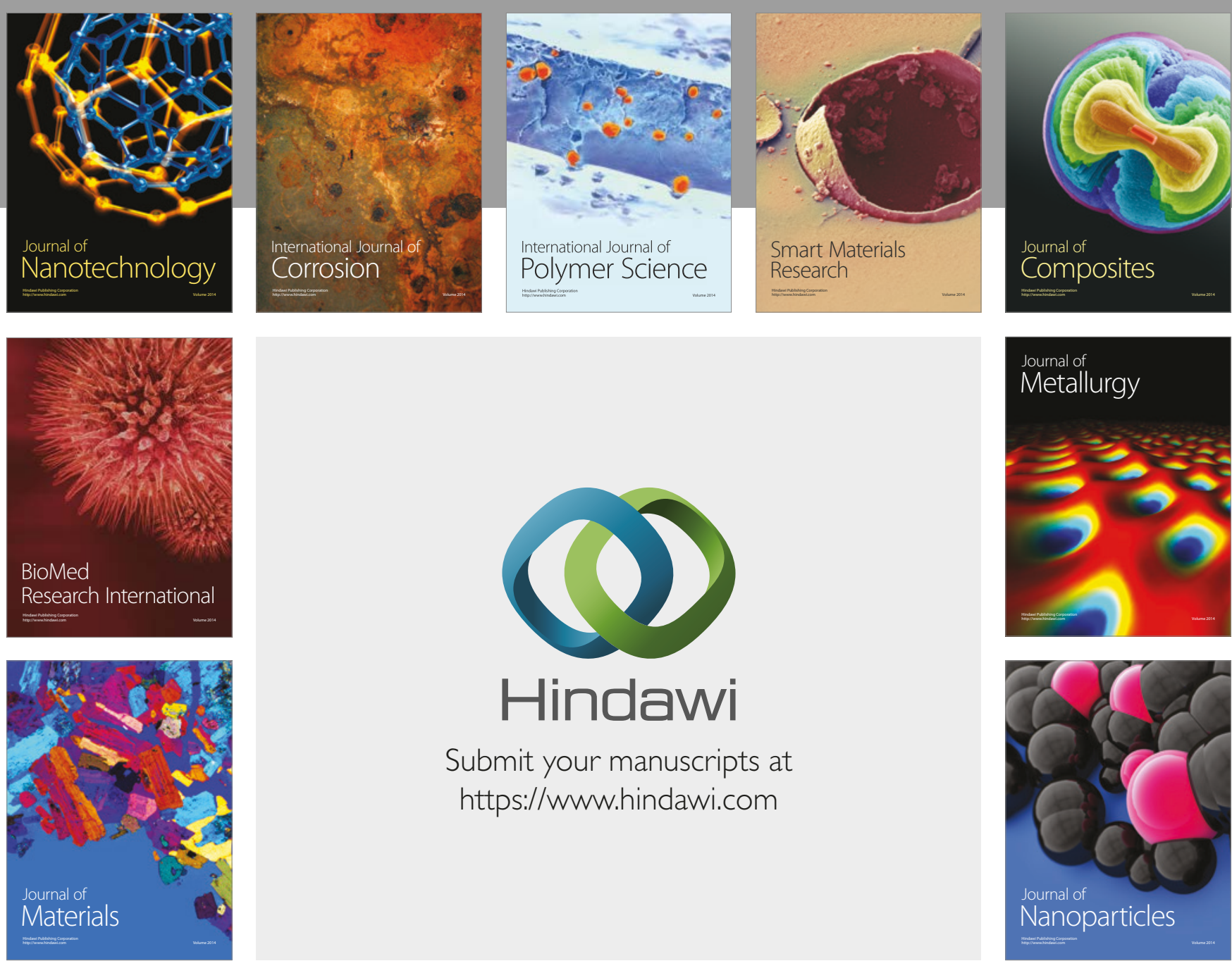

\section{Hindawi}

Submit your manuscripts at

https://www.hindawi.com
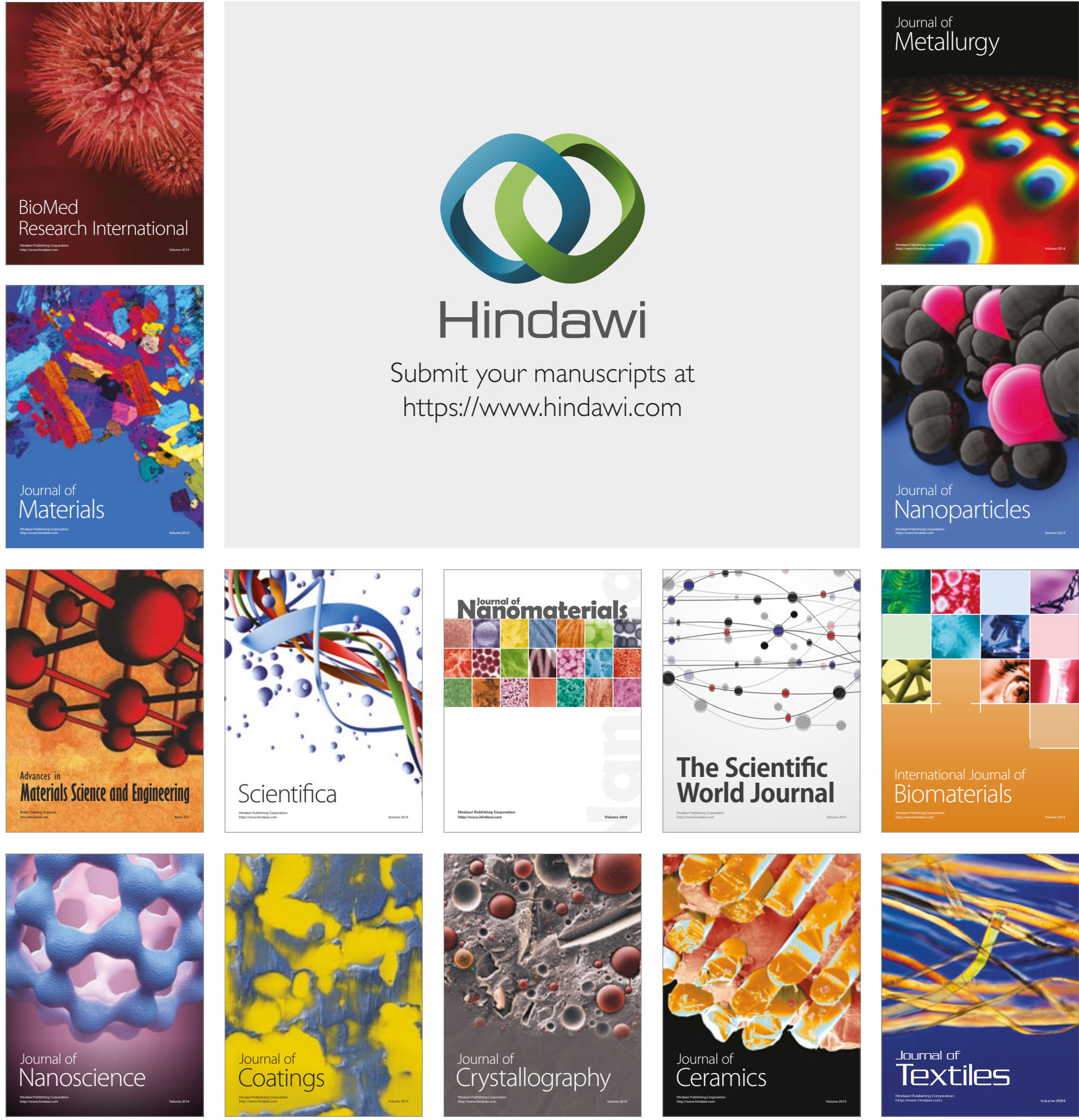

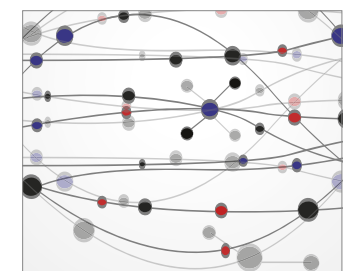

The Scientific World Journal
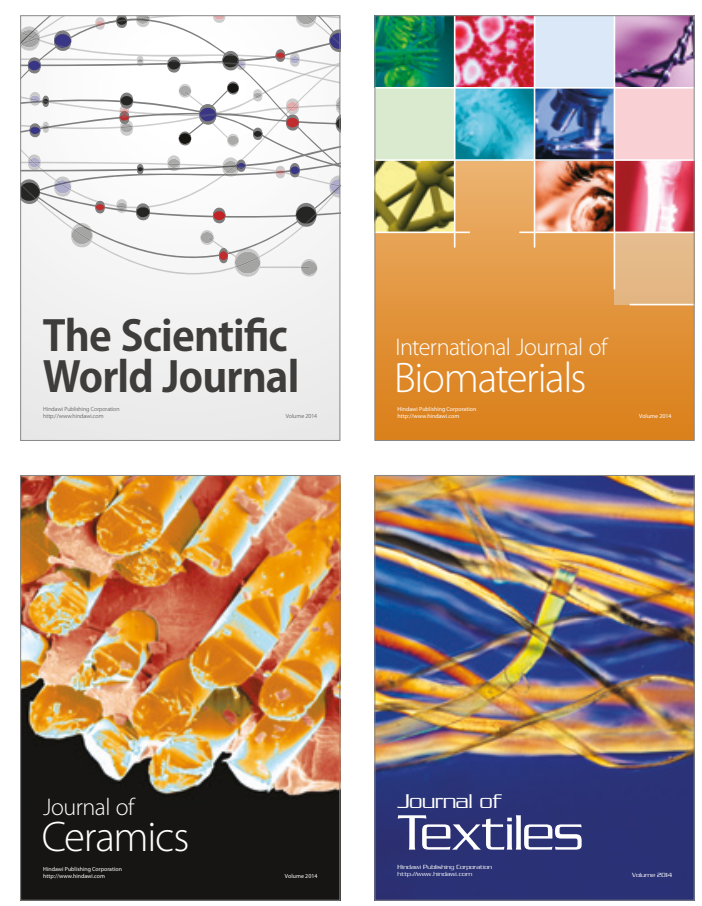